\title{
Comparative occurrence of diabetes in canine, feline, and few wild animals and their association with pancreatic diseases and ketoacidosis with therapeutic approach
}

\author{
Kamal Niaz ${ }^{1,2}$, Faheem Maqbool ${ }^{1,2}$, Fazlullah Khan ${ }^{1,2}$, Fatima Ismail Hassan ${ }^{1,2}$, Saeideh Momtaz ${ }^{2,3}$ and \\ Mohammad Abdollahi ${ }^{1,2,4}$
}

1. Department of Toxicology and Pharmacology, International Campus, Tehran University of Medical Sciences, Tehran, Iran; 2. The Institute of Pharmaceutical Sciences, Tehran University of Medical Sciences, Tehran, Iran; 3. Medicinal Plants Research Center, Institute of Medicinal Plants, ACECR, Karaj, Iran; 4. Department of Toxicology and Pharmacology, Faculty of Pharmacy, Tehran University of Medical Sciences, Tehran, Iran.

Corresponding author: Kamal Niaz, e-mail: kamalniaz1989@gmail.com

Co-authors: FM: faheemthepharmacist@gmail.com, FK: fazlullahdr@gmail.com,FIH: pharm.fatee@yahoo.com, SM: saeideh58_momtaz@yahoo.com, MA: mohammad.abdollahi@utoronto.ca

Received: 03-12-2017, Accepted: 26-02-2018, Published online: 05-04-2018

doi: 10.14202/vetworld.2018.410-422 How to cite this article: Niaz K, Maqbool F, Khan F, Hassan FI, Momtaz S, Abdollahi M (2018) Comparative occurrence of diabetes in canine, feline, and few wild animals and their association with pancreatic disease and ketoacidosis with therapeutic approach, Veterinary World, 11(4): 410-422.

\begin{abstract}
Diabetes mellitus (DM) is a chronic metabolic disorder in which blood glucose level raises that can result in severe complications. However, the incidence increased mostly by obesity, pregnancy, persistent corpus luteum, and diestrus phase in humans and animals. This review has focused on addressing the possible understanding and pathogenesis of spontaneous DM in canine, feline, and few wild animals. Furthermore, pancreatic associated disorders, diabetic ketoacidosis, hormonal and drug interaction with diabetes, and herbal remedies associated with DM are elucidated. Bibliographic search for the present review was done using PubMed, Scopus, and Google Scholar for articles on concurrent DM in small and wild animals. Persistent corpus luteal and pseudopregnancy in female dogs generate gestational DM (GDM). GDM can also be caused by extensive use of drugs/hormones such as glucocorticosteroids. Although many similarities are present between diabetic cats and diabetic humans which present islet amyloidosis, there was a progressive loss of $\beta$ - and $\alpha$-cells and the normal number of $\delta$-cells. The most prominent similarity is the occurrence of islet amyloidosis in all cases of diabetic cat and over $90 \%$ of human non-insulin dependent DM Type-2. Acute pancreatic necrosis (APN) occurs due to predisposing factors such as insulin antagonism, insulin resistance, alteration in glucose tolerance, obesity, hyperadrenocorticism, and persistent usage of glucocorticoids, as these play a vital role in the progression of APN. To manage such conditions, it is important to deal with the etiological agent, risk factors, diagnosis of diabetes, and hormonal and drug interaction along with its termination with suitable therapy (herbal) protocols. It should be noted that the protocols used for the diagnosis and treatment of human DM are not appropriate for animals. Further investigations regarding diabetic conditions of pets and wild animals are required, which will benefit the health status of all animals health worldwide.
\end{abstract}

Keywords: amyloidosis, diabetes mellitus, gestational diabetes mellitus, hypercortisolism, necrosis, pancreatitis.

\section{Introduction}

Diabetes mellitus (DM) is a chronic metabolic disorder in which the body's ability to produce or respond to the hormone insulin is impaired, resulting in abnormal metabolism of carbohydrates and elevated levels of glucose in the blood and urine. DM is one of the common and prominent metabolic diseases that have been diagnosed in canine and feline family after human beings. The clinical features described and investigated are rarely observed in other domestic large animals such as horse, cattle, buffalo, swine, and other small ruminants [1-3]. The propagation and mechanism of DM are almost similar in humans as well as animals, and thus, small laboratory animals

Copyright: Niaz, et al. Open Access. This article is distributed under the terms of the Creative Commons Attribution 4.0 International License (http://creativecommons.org/licenses/by/4.0/), which permits unrestricted use, distribution, and reproduction in any medium, provided you give appropriate credit to the original author(s) and the source, provide a link to the Creative Commons license, and indicate if changes were made. The Creative Commons Public Domain Dedication waiver (http://creativecommons.org/ publicdomain/zero/1.0/) applies to the data made available in this article, unless otherwise stated. are used in the etiopathogenesis, clinical trials, and research studies [4]. The main clinical feature of DM is thought to be the failure of $\beta$-cells to produce sufficient insulin for the metabolic pathway of the body organisms. The deceptive onset of DM depends on different factors: (a) Decline in the synthesis of insulin, (b) reduction in the sensitivity of the target cells or organs to the insulin, and (c) the excessive synthesis of other dependable hormones and drugs those are responsible for inducing DM [5].

The classification of diabetes differs for the large and small animals, although it has similarity to human. The common and general forms of DM are known to be insulin-dependent DM (IDDM) Type-1 and non-IDDM (NIDDM) Type-2 in animals. Also, the secondary DM or Type-3 has also been identified, which is the complication of the insulin antagonisms. This occurs due to the pancreatic islet damage by the pancreatic necrosis, tumor progression, and pancreatitis. Metabolic DM is the specific experimental expression of this form, primarily described in dogs and cats [2]. 
Clinical signs of non-ketoacidotic DM include polydipsia, polyuria, and polyphagia. In general, increased glycogenolysis and gluconeogenesis from amino acid source and little cellular uptake of the glucose trigger hyperglycemia in animals, which lasts for sometimes. Investigations have shown an association between the reduction of the glucose oxidation and such metabolic conditions. In addition, weight loss and atrophy of muscles are also associated with the abnormal gluconeogenesis of amino acid sources. Reduction in adipocyte fatty acid and increase in lipolysis will raise serum lipids, so huge amount of mobilized lipids will aggregate in the liver, which cannot be utilized or converted into lipoproteins. As a result, the liver gets enlarged uniformly with the condition of hepatomegaly. Ultimately, compensatory polydipsia, polyuria, osmotic diuresis, and glycosuria would happen due to the prolonged hyperglycemia and produce insistent high levels of glucose in urine. This will also exceed the threshold level of glucose restoration in renal tubules. Along with constant hyperglycemia, the failure of neurons in hypothalamic satiety and appetite center to uptake glucose will trigger appetite in animals [6].

This review aimed to elaborate the possible classification, etiology, and pathogenesis of spontaneous DM in small and wild animals, and also, focus on the innovative targeted researches in this area.

\section{Bibliographic Search}

Bibliographic search for the current review was carried out through PubMed, Scopus, and Google Scholar for articles on spontaneous DM in small and wild animals. The term included "DM in canine," "DM in feline," "amyloidosis," "pancreatitis," "classification of DM in small animals," "spontaneous diabetes in domestic animals," "spontaneous amyloidosis in wild animals," "glucose intolerance," "hyperinsulinemia in animals," and "insulin resistance in laboratory animals."

The retrieved data in this article were focused on studies related to small and some wild animals. The exclusion and inclusion criteria for the present search strategy are shown in Figure-1. The articles that provided data on DM from different countries were also hand searched, and those with internet base were collected using Google as a search engine. Therefore, the total number of studies (n) included in this review was 110 (Figure-1).

\section{IDDM Type-1 Diabetes in Dogs}

The IDDM Type-1 was first time investigated in 1861 in impulsive cases of dogs [1]. Next studies showed that this disorder particularly appears in females and old dogs even more complicated and enlarged, shortly after estrus period in pregnant females $[1,7,8]$. In this manner, progesterone production, which induces mammary growth hormone $(\mathrm{GH})$, plays a key role as it finally triggers DM in canine [9].
During the past decade, researchers focused on the etiological elements in dogs such as Dog leukocyte antigen (DLA) that promotes DM, responsible genes, autoantibodies, and their relationships [1,10].

It has been revealed in the studies conducted on the dogs $<12$ months of age that concurrent occurrence of adolescent disease is an unusual event $[11,12]$. Besides, more than $70 \%$ of diagnosed female dogs cases suggest that they are highly predisposed to DM [7]. Vice versa, some other studies claim that DM occurs equally in males and females [13]. Surveys demonstrated that ovariohysterectomy in the yearling stage seems to eliminate DM, as it will balance or remove the hormones that are responsible for triggering diabetes commencement. It also elucidates that the incidence of DM is high in pregnant female dogs and estrous cycle.

Table-1 $[7,13,14]$ provides various epidemiological studies conducted in the UK, North America, and Sweden, which have explored DM mainly in the different breeds of dog (e.g., Dachshund, Beagle, Lhasa Apso, Yorkshire terrier, Spitz, and Labrador retriever). Islet hypoplasia is known as the predominant and common problem in Golden Retriever and Keeshond in their first age of life. The most popular and widespread breeds such as German Shepherd and Boxer appear to be tough against DM. Usually, the $\mathrm{DM}$ in canine can be clinically identified at the age of 4-18 years, whereas the best average age is $7-9$ years providing authentic results $[7,13,14]$.

The general damages of islets of Langerhans almost have seen in all kind of dogs. Approximately $50 \%$ of recent identified dog cases suggested that $\beta$-cell damage may be due to autoantibodies [15]. Comparing with IDDM in cattle and humans some diabetic dog shows serological reactivity to $65 \mathrm{kDa}$ isoform of glutamic acid decarboxylase (GAD) or insulinoma antigen-2 $[13,16]$. The genes responsible to initiate DM in canine and humans such as tumor necrosis factor-alpha (TNF- $\alpha$ ), TNF- $\gamma$, interleukin-4 (IL-4), IL-10, IL-6, IL-12 $\beta$, insulin, and protein tyrosine phosphatase non-receptor Type 22 and their defensive association links have been described [1]. DLA is also known as canine major histocompatibility complex gene that acts effectively in the initiation and triggering of canine DM. Dog breeds such as Tibetan Terrier, Cairn Terrier and Samoyed explicit haplotype of major histocompatibility complex, DLA DRB1*009/DQA $1 * 001 / \mathrm{DQB} 1 * 008$ matching with non-diabetic breeds or resistant breeds [1]. It has been revealed previously that the IDDM occurs in the Keeshonds breeds due to the presence of an autosomal recessive gene $[17,18]$.

In most of the diagnostic cases in canine etiopathogenesis of DM, this is still uncertain. The appearance of DM in canine happens through different routes and due to many risk factors; therefore, the classification of diabetes in canine looks to be challenging. Inappropriately, the human 


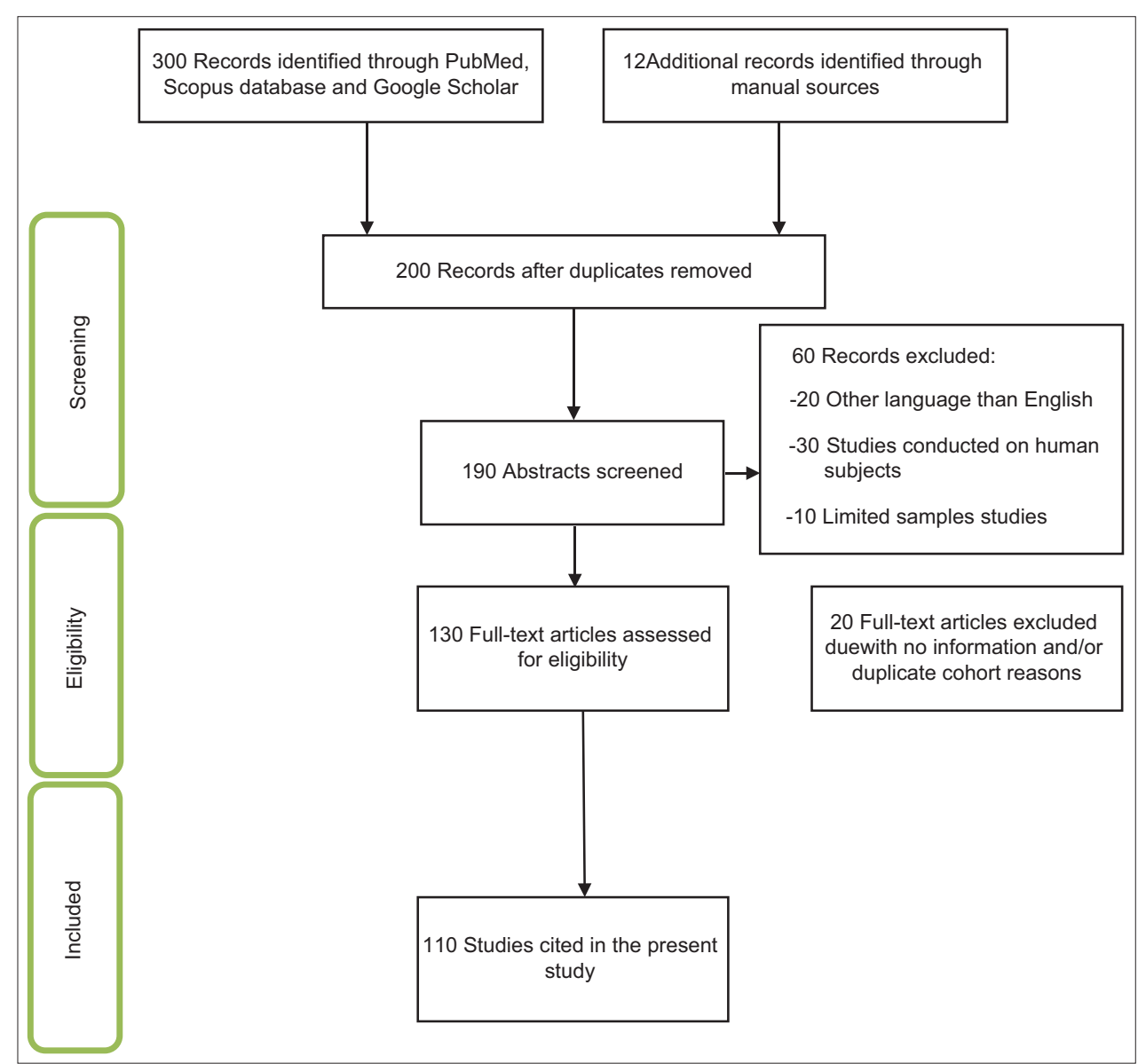

Figure-1: Flowchart of included studies; illustrates the number of citations and resource materials that have been screened, excluded, and/or included in this review.

Table-1: DM commonly occurred in different breeds of dogs.

\begin{tabular}{llr}
\hline Countries & Breeds & References \\
\hline UK study & Samoyed, Tibetan Terrier, and Cairn Terrier & {$[13]$} \\
North America study & Miniature Schnauzer, Miniature Poodle, Bichon Frise, Samoyed, and Cairn Terrier & {$[14]$} \\
Swedish study & Australian and Samoyed Terrier, Swedish Lapphund, Swedish Elkhound, and & [7] \\
& Border Collie & \\
\hline
\end{tabular}

DM=Diabetes mellitus

classification of DM is found difficult to apply in dogs, since NIDDM Type-2 in dog shows uncertain and needs administration of insulin earlier or late in nearly all diabetic dogs. Furthermore, it was recommended that DM characterization in dogs depend on the pathogenesis rather than the response to insulin therapy [1]. The present diagnosis and therapy consider a classification system of DM in canine are primarily based on the underlying cause of hyperglycemia; insulin resistance diabetes and insulin deficiency induce diabetes (Table-2). Importantly, insulin resistance diabetes would take over insulin deficiency diabetes based on $\beta$-cell fatigue and glucotoxicity (Figure-2) [1].

In some of the dog breeds such as Golden Retriever, Dachshund, and Shetland Sheepdog, obesity and DM have an imperative association; as in fully obese dogs, there will be unusual glucose xenophobia and high level of insulin $[19,20]$. Later on, it was determined that DM in the obese dogs could be classified on the basis of the reaction to the glucose administration. In the first group with abstaining hyperinsulinemia, there was a worthy response to the glucose level by increasing insulin secretion, and in the second group, no response to the glucose administration was highlighted by fasting excessive insulin in the blood. These results indicated that there was a low level of insulin in obese diabetic dogs as compared to obese non-diabetic dogs [21]. Lai et al. [22] reported that high-fat foods trigger successive insulin resistance which is not followed by excessive insulin in the circulatory system and ultimately lead to DM and glucose intolerance. Despite information above, DM initiated by insulin resistance and high insulin level in dogs is considered as an uncommon condition. Occasionally, persistent corpus luteal and pseudopregnancy in female dogs generates gestational DM (GDM); furthermore, the extensive use of artificial 
Table-2: Characterization of DM in dogs.

\begin{tabular}{ll}
\hline Type of diabetes & Effects \\
\hline Insulin deficiency, diabetes & Hypoplasia of $\beta$-cells, immunity facilitating $\beta$-cell damage, $\beta$-cell loss \\
(damage of $\beta$-cells and complete lack of insulin) & $\begin{array}{l}\text { due to pancreatitis and necrosis, idiopathic processes } \\
\text { Obesity, estrous cycle, pregnancy, endocrine disorders }\end{array}$ \\
$\begin{array}{l}\text { Insulin-resistant diabetes } \\
\text { (comparative insulin deficiency due to insulin }\end{array}$ & $\begin{array}{l}\text { (acromegaly and hyperadrenocorticism), glucocorticoids, and } \\
\text { antagonists or simultaneous conditions) }\end{array}$ \\
\hline
\end{tabular}

DM=Diabetes mellitus

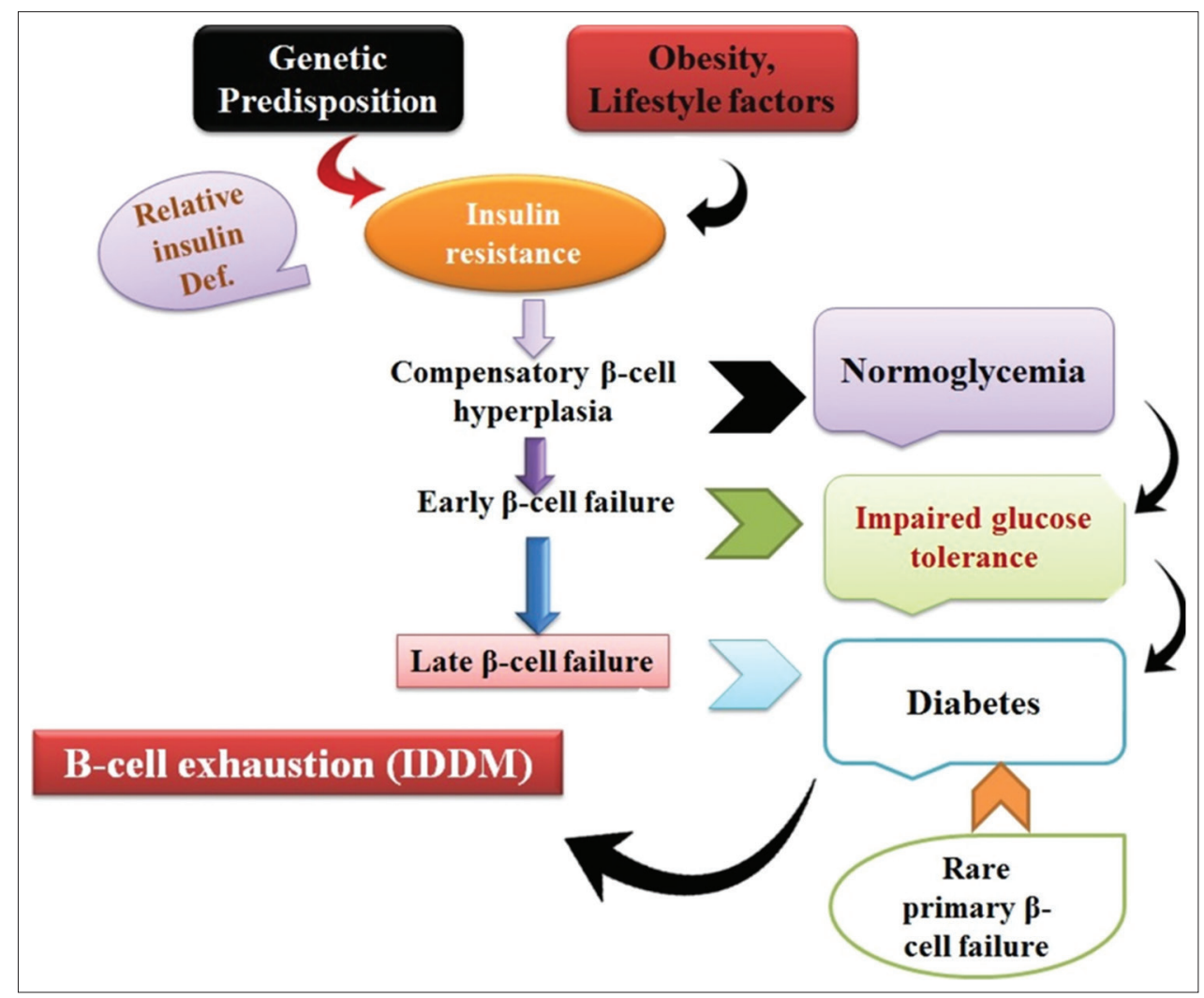

Figure-2: Simultaneous occurrence of insulin-dependent diabetes mellitus (IDDM) and non-IDDM in animals. Source: Designed by authors FK and FIH.

gestagens such as megestrol provokes DM by vacuoles formation in the $\beta$-cells [23].

Very few studies stated that GDM mostly occurs during the estrous cycle in dogs $[7,8,24]$. During fetus development, vital metabolic changes happen to assist the new developing fetus. Throughout the pregnancy, there would be an increased level of lipid metabolism, high insulin secretion, higher energy diet, and peripheral insulin resistance, and accordingly, these metabolic changes will offer the energy in the form of amino acids and glucose for newborn growth. The surplus lipids already stored in the adipose tissue are being used as an alternate source for female maintenance and survival. These efficient functional and morphological changes also induce hyperplasia and hypertrophy in the islets of Langerhans $\beta$-cells and activate insulinemia, which sustains normal glycemia ultimately [25]. The failure of the adaptive mechanism leading to GDM in canine, as previous findings, proved that hormones such as lactogens, prolactin, cortisol, and progesterone can generate peripheral insulin resistance. Progesterone plays an important role in the development of GDM as initiates' mother $\mathrm{GH}$ and prompts anti-insulin activity [26]. In general, glucose toxicity occurs due to the lack of insulin and damage of the $\beta$-cells. Higher levels of GH and cessation of GAD-65 autoantibodies present during diestrous phase in pregnancy and pseudopregnancy [8]. Verdicts of above studies reveal that reproductive hormones are also crucial for the initiation of $\mathrm{DM}$, and likewise, surgical procedure as ovariohysterectomy and termination of pregnancy gives good extensive enhancement [8]. Note that, almost more than $50 \%$ of affected animals would normalize the following procedures. Together, these investigations demonstrated in aged animals, and DM will be a permanent condition due to the reduction and exhaustion of $\beta$-cell ooze as well as the declined time of tolerance to hyperglycemia.

\section{NIDDM Type-2 Diabetes in Cats}

In cats, NIDDM most frequently emanates post-pathological conditions encountered by endocrine system disruption [27]. DM in cats shows the same clinical and pathological characteristic as human 
Type-2 diabetes restricted to individual characteristics such as obesity, median, and older age, following lower blood insulin level or the aggregation of amyloids in islets of Langerhans with damaged $\beta$-cells, and finally lead to retina and neural complications (Figure-3). The administration of drugs/hormones such as corticosteroids, progesterone as well as various diseases such as acromegaly, hyperthyroidism, renal, cardiac conditions, and hypercortisolism trigger insulin resistance in cats. Also, cats express extra insulin dependency and ketoacidosis [28-31]. IDDM exploration seems problematic in cats: As $\beta$-cell antibodies did not prove any involvement in the pathogenesis of diabetes in cats, besides the rare inflammation of lymphocytic islets of Langerhans [32,33].

In cats, secretion of insulin decreases as a response to glucose during the first phase of DM, following an exaggerated response in the second phase at early stages of the disease. Induction of glucotoxicity, lipid toxicity, and the islets of Langerhans amyloid disease strongly are involved in the initiation and development of DM, especially NIDDM Type-2 in cats. The first confirmatory model in cats exhibited the harmful effects of glucose on islets of Langerhans after long therapy of intraperitoneal administration of glucose to form vacuole in Langerhans cells that have led to DM. The structural and functional damages of $\beta$-cells and target tissue of insulin could be the main aim of therapy protocol of hyperglycemia to protect $\beta$-cells and lessening of DM. Glucose is responsible for the initiation of insulin synthesis through simulating dictation of insulin gene by phosphorylation of pancreatic and duodenal homeobox 1 (PDX1). It has been reported that glucotoxicity and hyperglycemia initiation might appear due to the reduction of insulin, PDX1, and $\beta$-cell deregulation of glucose transporters on membrane. Early death and exhaustion of $\beta$-cells were observed as the result of the endurance of hyperglycemia for more than 10 days. Extraordinary oozes of insulin and $\beta$-cell damages elucidate glucotoxicity $[34,35]$.

Reusch [31] showed basal insulin resistance, and the initial stage of DM happens through the interaction between excessive reaction to glucose and hyperinsulinemia. Amyloids degradation of islets of Langerhans and debilitation of $\beta$-cells are typically supplemented by remunerative insulin production and secretion failure, which leads to explicit DM. In addition, early stages of the disease in cats did not need insulin, while later on, it becomes a compulsory component [31]. There are significant values regarding the incidence of DM in certain population like $0.43-2.24 \%$ substantially in Burmese cats. Comparing the sex and age of cats, DM is prominent in male and significantly more advanced in older ( $>13$ years of age) associating with long-haired and small pet breeds [36-38]. DM in adolescence was infrequently characterized. The most diagnostic features such as hypoplasia of islets of Langerhans and blurred vision due to the diabetic bilateral cataract involving cortex and nucleus also help to classify DM in cats [12]. The symptoms of occurrence are similar with human's diabetes; the diabetic cats persisted amyloid disease, damage to $\alpha$-and $\beta$-cells, while normal $\delta$-cells. However, these disorders do not impair glucose tolerance, and still, it has some vital influence in the pathogenesis of DM [33].

In domesticated and wild cats, more than $80 \%$ identified cases of NIDDM showed islets of Langerhans amyloid disease typical appearance $[38,39]$. The quantity of amyloid protein aggregation increases with age and typically identified in normal and healthy cats as well. The amyloid disease condition is much pronounced in diabetic individuals as compared to the non-diabetic one. The existences of high levels of amyloid protein lead to the devastation of $\beta$-cells, diminishing of $\beta$-cell activity, and high stimulation of $\beta$-cells. Aggregation of amyloid in extra- and intra-cellular space in non-endocrine

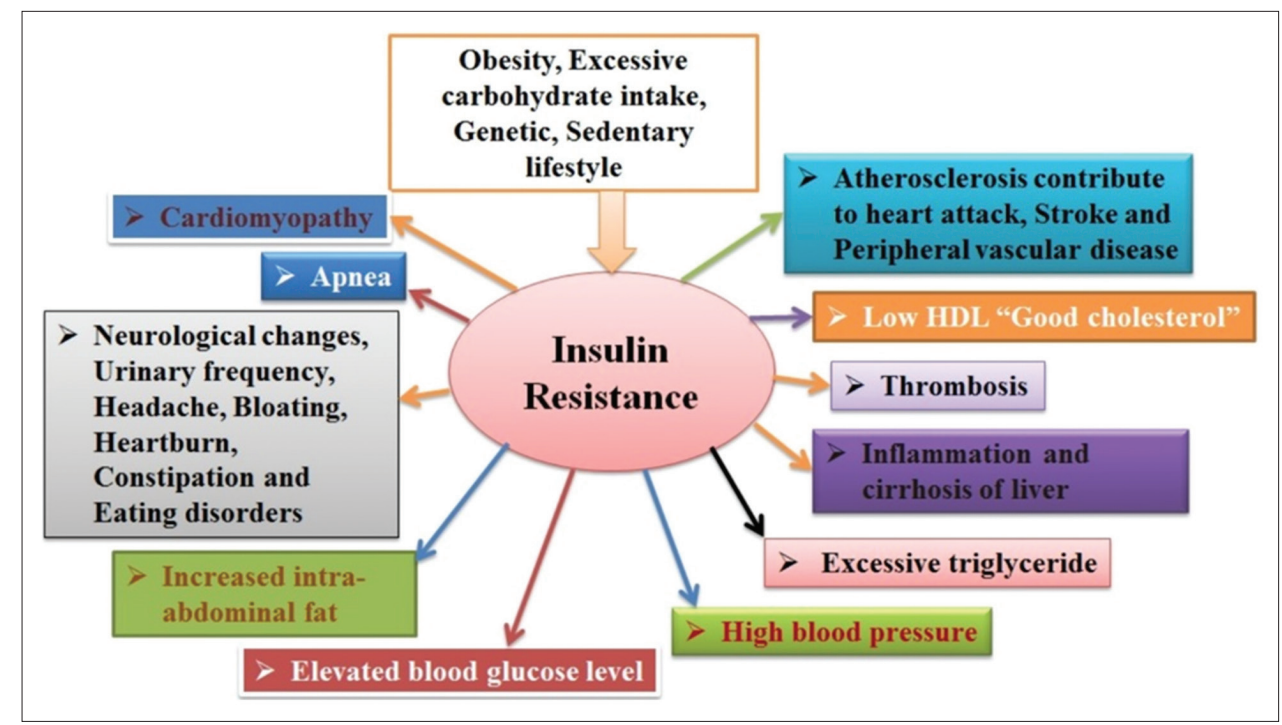

Figure-3: Complication occurred due to diabetes mellitus in animals.

Source: Designed by authors FK and FIH. 
cells of islets of Langerhans causes cellular death and additional cellular membrane interruption [40]. The by-products of amylin peptide hormone cosecreted with insulin from $\beta$-cells are predicted to impair glucose tolerance. Amylin also known as islet amyloid polypeptide (IAPP) inhibits glucagon secretion and deficient in diabetic patients $[30,41,42]$. The concentration of IAPP has been reported to be high in hyperinsulinemic clamp and obese cats with diminished glucose resistance. Not only a high concentration of IAPP is compulsory for islet amyloid protein formation but also other mechanisms such as malformation of $\beta$-cells, emission, carrying, and deprivation of IAPP may also be involved [43]. A robust association between IAPP and initiation of Type-2 diabetes were detected in both humans and cats. Likewise, the initiation of DM in cats is accompanied due to the obesity in correlation with high concentrations of IAPP and insulin in non-diabetic individuals [44]. Findings suggest that hyperglycemia also happens due to the inhibitory effect of amylin hormone on glucose-exciting insulin formation, which at last enhances gluconeogenesis. Glycogenolysis and reservation of glucose intake develop regarding IAPP persuaded insulin conflict in muscle. It was assumed that secondary obesity occurs when glucose yields from muscle glycogenolysis, which has been recycled in the process of conversion of acetyl-CoA to fatty acid as IAPP, do not affect fat tissue [45].

Aggregation of non-adipose tissue around the heart, liver, pancreas, and skeletal muscle along with unnecessary high levels of triacylglycerol (TAG) initiates lipid toxicity. Moreover, insulin resistance takes place due to the excessive accumulation of TAG in $\beta$-cells, which will exhaust these cells and alter insulin synthesis. The existence of TAG in these cells could be insufficient to persuade small quantity of insulin and insulin resistance. It is understood that fatty acids are generating peroxidation compounds and toxic lipid intermediates due to the production of TAG and hydrolysis of triglycerides along with lipolysis. In addition, the alteration in insulin signaling of $\beta$-cells and liver initiated by TAG, and toxic lipid intermediates substantially promote the expression of the genes responsible for death. Li et al. [46] have indicated that in non-adipose tissue, insulin resistance and lipid toxicity are initiated by vital long-chain 3-hydroxy acyl-coenzyme-A dehydrogenase (LCHAD). Similar mechanism involves in skeletal muscle. They also reported that low intracellular glucose concentration usually correlates with higher levels of LCHAD in sarcoplasm. Furthermore, insulin resistant in humans and animal individuals shows high intramuscular quantity of LCHAD [46].

Mass of adipose tissue is supposed to be associated with the effectiveness of insulin to lessen basal glucose concentration. Male cats with heavyweight have a failure in insulin sensitivity, while commonly lean male cats have less insulin delicate than lean female cats. Obese male cat develops hyperinsulinemia faster than obese female individuals, and high insulin resistance can be observed in high abdominal fat aggregation. It has been explored that cats' breed such as Burmese has excessive abdominal fats accumulation and low subcutaneously [37]. Moreover, not only obesity results in DM but also the onset of diabetes involves smaller improvement in body weight gain and adipocytes increase. Statistics suggested that $25 \%$ of cases showed insulin sensitivity due to the slight weight gain as compared with diabetic individuals [47]. Alteration of internal oxidative glucose metabolism and less compatibility of insulin receptors leads to more insulin resistance.

As described earlier, low level of glycogen in liver cell cytoplasm and sarcoplasm leads to the higher insulin resistance. In addition, IAPP inhibits glycogen synthetase and glucose uptake and increases glycogenolysis followed by lactate synthesis. Subsequently, gluconeogenesis is begun soon after liver uptakes lactate. So far, three main insulin signaling genes are recognized as key elements in liver and muscle of moderate obese cats: (1) Phosphatidylinositol 3 kinases $p-85-\alpha$, (2) insulin receptor substrate-1 (IRS-1), and (3) IRS-2. The incidence of insulin resistance in NIDDM showed similarity in both feline and humans [48].

Alteration in glucose tolerance and insulin resistance peruses a significant influence on NIDDM, such as obesity [49]. Obesity and compensatory excessive circulatory insulin trigger low tissue sensitivity to insulin. Figure-2 depicts multifactorial causes of obesity such as genetics, nutrition, and environment. Rand et al. [50] have reported that the lack of nutrition leads to lipid degradation and excessive food toxicants, which as a result initiates lipid formation based on a genetic factor in the existence of energetic thrifty genotype. In addition, consumption of an excessive amount of edible diet with extra supplementation of carbohydrates, aging, castration, vasectomy, hysterectomy, and the little physical workout is also counted as important factors [51]. Higher concentrations of IL-1 $\beta$, IL-6, C-reactive receptors, leptin, resistin, and TNF- $\alpha$ indicate the initiation of obesity and insulin resistance (Figure-4). It has been stated that mainly, insulin receptors that have been blocked by TNF- $\alpha$ would affect insulin sensitivity [49].

\section{DM in Wild Animals}

Concurrent occurrence of DM in humanized and non-humanized primates was identified in confined animals. Clinical and morphological characteristics in restricted animals explored as NIDDM Type-2. Various studies suggest that insulin resistance causes alteration of $\beta$-cell activity and prolong pre-diabetic conditions and thus also has shown resemblances of NIDDM in both humans and non-human primates. As yet, synchronized amyloid disease has been identified in different animals: Pan troglodytes (chimpanzee), 


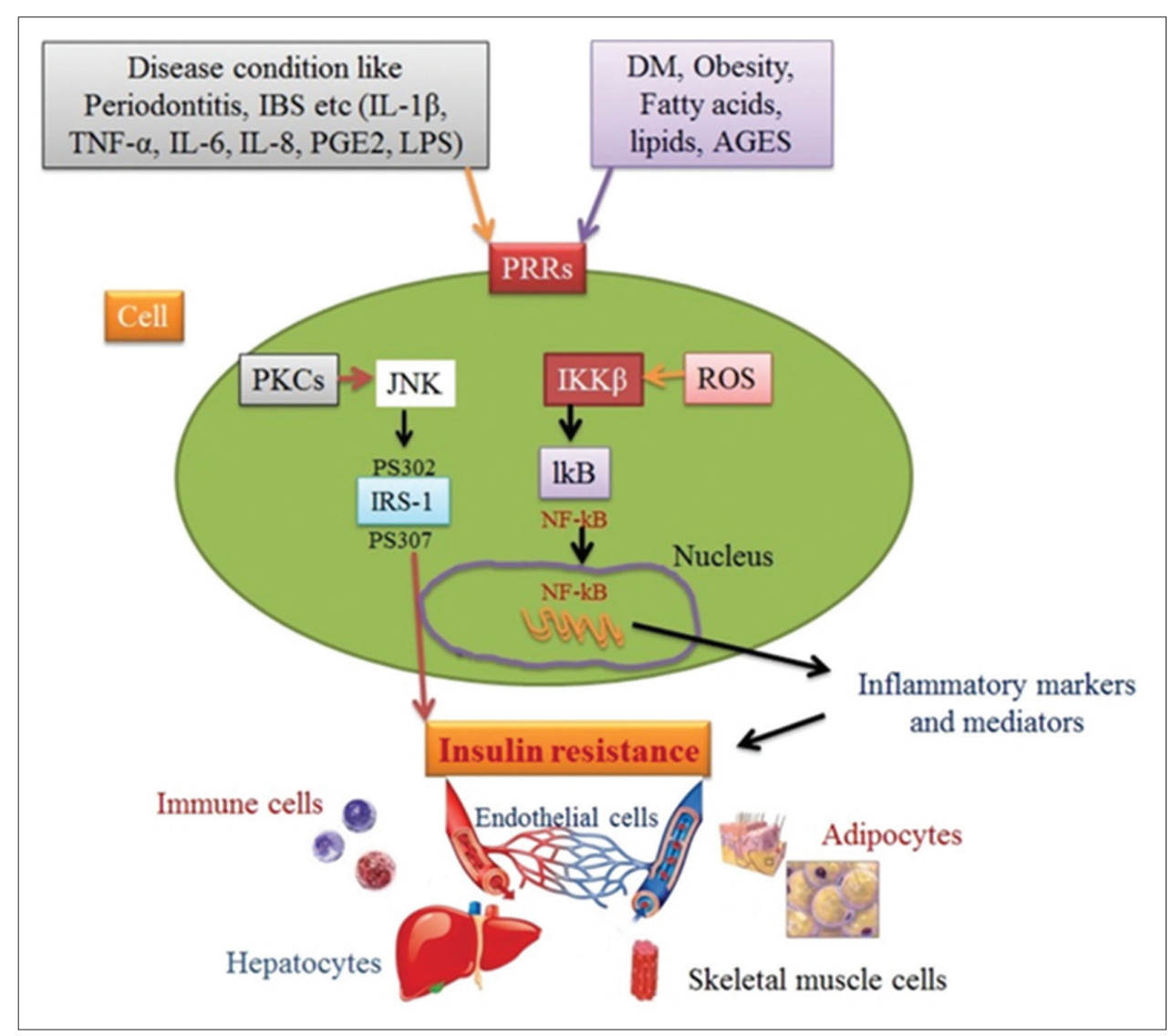

Figure-4: Mechanism initiating insulin resistance.

Source: Designed by authors FK and FIH.

Pongo pygmaeus (orangutan), Cercopithecus species, Macaca species, Mandrillus species, Papio hamadryas, Saimiri sciureus, and Macaca mulatta [52-58]. Aggregation of amyloid protein has been identified in different organs such as in the liver, kidney, pancreas, spleen, and adrenal gland. In research by Hubbard et al. [57], immunohistochemical analysis of IAPP, calcitonin family peptide, and calcitonin gene-related peptide showed positive aspects of islets of Langerhans amyloid disease. Histopathological lesion assays showed that amyloid protein accumulation throughout capillaries and in pancreas cells has serious harmful effects that were similar to those defined in cats $[53,57,59]$.

Fibrosis of islets of Langerhans and chronic pancreatitis was identified in Procavia capensis (rock hyrax) and California sea lion, describing another type such as secondary DM [60,61]. Panthera onca, African spotted leopard, and even their progeny developed DM in confined conditions $[62,63]$. Consequently, the extensive use of humanized hormone-megestrol acetate to prevent pregnancy and following subtype of breast cancer leads to elucidate secondary DM in Panthera onca [62].

DM in older primates causes disorders such as venous thrombosis, nephropathy, myocardial fibrosis, and cardiomyopathy [64]. Non-humanized primates such as monkey initiate pituitary adenoma, which is a favorable situation to insulin antagonism leading to secondary DM [65]. The study of Spermophilus lateralis was one of the comprehensive and widely investigations that exhibited the presence of DM in confined rodents. Obviously, these animals are mostly characterized by blurred vision, retinal atrophy, and opacity, plus the vacuole formation has been observed in their islets of Langerhans in both $\alpha$-and $\beta$-cells [66]. Rodents such as Ctenomys talarum and Lagostomus maximus provoked DM in progeny as well as in adults with noteworthy high levels of fructosamine, glucose, fatty liver, opacity, and blurred vision $[67,68]$. It is hypothesized that diminishing exercise, excessive diet, and more glucose consumption appear to be other reasons for DM as well. It seems that a few months of confinement elucidated IDDM Type-1 in individuals and their progeny such as in Clethrionomys glareolus. Certain animal studies have illustrated that IDDM shows specific indications, such as islets of Langerhans vacuole formation, and insulin autoantibodies, such as islet antigen-2 and GAD-65. In the pancreatic islets, vacuolization picornavirus was also recognized $[69,70]$.

The granivores bird predators have different strategies for the metabolism of glucose as compared with other mammals. Although there were high concentrations of glucose in birds as compared with other vertebrates matching body weight, lower intracellular glycogen and plasma glucose level were not controlled by insulin involvement. Three various types of islets of Langerhans are responsible for the synthesis, 
production, and secretion of the avian pancreatic polypeptide, somatostatin, insulin, and glucagon [71]. The glucagon concentration in birds is greater than mammals, due to its activities toward glucose metabolism as well. The well-organized mechanisms, which make birds urine free of glucose, also need glucose transport protein and sodium-glucose co-transporters to absorb glucose from gastrointestinal tract [72]. Perhaps, in conclusion, it may be suggested that lower insulin and higher glucagon are significant for provoking DM [71]. Another study in ducks proposed that surgical removal of pancreas express hypoglycemia. Indeed, there were controversies as administration of anti-insulin serum, and partial surgical removal of pancreas elucidates DM in ducks and gooses. Furthermore, in few cases of birds, DM was fruitfully achieved by long-term insulin therapy [73].

Van Der Kolk et al. [74] exhibited in bulls which have chronic laminitis, polyarthritis, and traumatic injuries of the penis with edema treated by chlorothiazide, dexamethasone, phenylbutazone, and prednisolone expressed islets of Langerhans atrophy and fibrosis. The authors stated that Elephantid herpesvirus- 1 could be the possible source of this condition and treatment procedure should also contain the essential factor such as the use of insulin antagonist. Nevertheless, Psittacid herpesvirus-1 in the pancreas was infrequently found, but differential diagnosis of bird pancreatitis with or without DM is important. Interestingly, a significant linkage between DM and extreme iron deposition was monitored in Ara severa, Ara militaris, and humans [75]. Studies of iron overloading revealed the presence of insulin insufficiency related to deposition of iron in $\beta$-cells in humans and rodent [76]. In a dispute, no prominent lesions were found in islets of Langerhans. Still, long-term protocol flourished birds survival for about 1.5 years [75].

In raptors, DM is rarely reported, while in carnivorous birds such as a great horned owl, surgical pancreatectomy resulted in hyperglycemia and consequently caused death. Concurrent DM was also identified in female Buteo jamaicensis, where the main lesions such as air sacculitis, bronchopneumonia, and cysts are formed in proximal tubules linked with interstitial lymphocyte nephritis. Although individual foci were identified in fatty liver syndrome, the absence of typical glycogen granules and $\beta$-cells was limited with severe deterioration of islets of Langerhans. However, both histological and bacteriological examination revealed cocci in the lungs and kidneys with no bacterial clusters, respectively. Hence, the etiology lasted mysteriously, and no tumor in pituitary and adrenal glands was observed [77].

The clinical diagnostic lesions such as ketonuria, renal glucosuria, hypoinsulinemia, hyperglycemia, polydipsia, and polyuria were found infrequently in species such as in Ara severa and Nandayus nenday [78,79]. The absence of immune histochemical reaction to insulin nearly damages all islets of
Langerhans. Almost in the entire conditions of exocrine pancreas, clinical autoimmune pancreatitis was identified [78]. The islets of Langerhans hypertrophy and remunerative proliferation were investigated in Psittacus erithacus, in which the damage was elucidated by pancreatic inflammation [80]. Bacteria and viruses were also found in simultaneous cases, such as Pacheco's disease caused by Psittacid herpesvirus that is presented in lymphoplasmacytic pancreatitis in Nymphicus hollandicus diagnosed with IDDM [81]. The analysis showed the similarity of this disorder with Psittacines and was highlighted in intestinal crypts, parathyroid, thymus, nuclear inclusions, cytoplasmic inclusions, syncytial cells in respiratory epithelium, and hepatic/renal and splenic necrosis $[82,83]$. Table-3 provides an overview of the existing animal models, which are used to evaluate different types of DM in animals.

\section{Diabetes and Pancreatic Disease}

The characteristic lesions of chronic pancreatitis include fibrosis, cyst formation in pancreatic ducts, lymphocytic penetration, and atrophy of parenchyma [84]. Simultaneous slight incidents of acute pancreatic necrosis (APN) and acute pancreatitis provoke chronic inflammation. The initiation of DM in dogs, cats, and other wild animals due to the chronic pancreatitis is not always responsible for inducing degeneration of pancreatic islets. The endocrine and exocrine deficiencies may develop over the excessive fibrosis, trophy, and lympho-plasmatic penetration in the pancreas. However, this is also noteworthy that DM occurrence related to chronic pancreatitis has been reported in nearly $30 \%$ of identified cases in association with histological characteristic [85]. Breeds' predispositions exhibited a positive association with the incidence of DM, while old-aged dogs and cats demonstrated wide damages of parenchyma and secondary DM regulated by different morphological forms of adenocarcinoma of the pancreas $[3,86]$.

The degeneration of islets of $\operatorname{dogs}$ and cats through the pancreatic necrosis is followed by the acute and chronic pancreatitis and tumor formation. Primarily, the dominance of tumor and inflammation encloses canine APN and acute pancreatitis. The term APN is used for tumor, is reliable, and thus is signified with inflammation. APN rarely occurs in cats, is sporadic in pigs, and deliberately is considered as the main reason of DM in dogs. Therefore, the initiation of DM is regulated by various influencing features of APN. Predisposing factors such as insulin antagonism, insulin resistance, glucose tolerance alteration, obesity, hyperadrenocorticism, and persistent use of glucocorticoids are also associated with APN. Further, along with these, other complications take place if DM is not properly noted and treated (Figure-3). Acute inflammation of the pancreas expresses diabetic ketoacidosis, whereas ketonuria exists as fatal APN in most of the dogs. Typically, acute pancreatitis and ketonuria 
Table-3: Existing animal models for the assessment of DM.

\begin{tabular}{|c|c|c|}
\hline Animal model & Type of animals used & Experimental parameters \\
\hline Normoglycemic & Normal healthy animals & Potential oral hypoglycemic agents are tested \\
\hline $\begin{array}{l}\text { Oral glucose loading model } \\
\text { (glucose tolerance testing) }\end{array}$ & Normal healthy animals & $\begin{array}{l}\text { Physiological induction of DM in animals; glucose } \\
\text { level is monitored }\end{array}$ \\
\hline Streptozotocin model & Normal healthy animals & $\begin{array}{l}\text { Streptozotocin induces DM over a period; } \\
\text { provides suitable time intervals and additional } \\
\text { information for the mechanism of action of drugs }\end{array}$ \\
\hline Alloxan model & Normal healthy animals & $\begin{array}{l}\text { Alloxan induces DM; provides the possibility } \\
\text { to produce different grades of severity of DM; } \\
\text { provides the blood sugar levels equivalent to total } \\
\text { pancreatectomy }\end{array}$ \\
\hline $\begin{array}{l}\text { Ferric nitrilotriacetate induced DM } \\
\text { model }\end{array}$ & Normal healthy animals & $\begin{array}{l}\text { Measures diabetic symptoms (hyperglycemia, } \\
\text { glycosuria, ketonemia, and ketonuria) }\end{array}$ \\
\hline Surgical model & Normal healthy animals & $\begin{array}{l}\text { DM is induced in removed } \\
\text { pancreas (pancreatectomy); permits to assess } \\
\text { if the drug affects resistance to and secretion } \\
\text { of insulin }\end{array}$ \\
\hline Genetic model & $\begin{array}{l}\text { Genetically engineered animals } \\
\text { or mutant strains }\end{array}$ & $\begin{array}{l}\text { Long-term complications of DM could be } \\
\text { monitored; several drugs could be tested against } \\
\text { DM; measures (blood sugar, body weight, insulin } \\
\text { production, and insulin resistant); explores the } \\
\text { mechanism of action of drugs }\end{array}$ \\
\hline
\end{tabular}

DM=Diabetes mellitus

along with APN develop DM so that pancreatitis may progress due to the DM. Hypertriglyceridemia condition in diabetic dogs presents as threat feature for pancreatitis $[87,88]$.

Tumors of islets of Langerhans are rarely diagnosed in dogs. Pancreatic tumors cause secretion of the excess amount of hormones, as most of the diagnosed dogs and ferrets exhibited immoderate levels of hormones in histological examination. DM is also related with glucagonoma of the pancreas and is included by antagonism of glucagon through insulin. Both mechanisms of hepatic glycogenolysis and gluconeogenesis are responsible to elucidate hyperglycemia and extreme secretion of glucagon $[3,89]$.

\section{Non-ketotic Hyperosmolar Diabetes (NKHOD) and Ketoacidosis Diabetes}

Hyperglycemia, osmotic diuresis, and hyperosmolarity followed by dehydration are termed NKHOD. Accordingly, coma, hyperthermia, seizures, ataxia, convulsions, and nystagmus are the deleterious clinical features of the central nervous system [90]. The most prominent and severe complication of DM in dog and cats is ketoacidosis. The elevation of blood insulin antagonists such as cortisol, glucagon, and monoamines, along with the enhancement of hormones, generates stressful conditions due to the poor management of insulin treatment. Additional disorders such as pancreatitis, necrosis, infection, Cushing syndrome, immune suppression, renal, hepatic, and heart failure trigger simultaneous DM. Such conditions initiate lipolysis and make liver to accumulate more fatty acids regarding survival and body maintenance. Acetoacetic and $\beta$-hydroxybutyric acids are formed due to deficiency of insulin and glucose, which in turn facilitate oxidation of triglycerides. Certain ketoacids are modified into acetones and exhale air contained acetones and ketones in the breathing air [91]. Clinical features such as hypovolemic shock, dehydration, and excessive loss of magnesium, sodium, potassium as well as conditions like ketonemia, ketonuria, acidosis, and hyperglycemia provoke ketoacidosis [92].

\section{Hormones Associated with DM and Drugs}

Acromegaly is expressed as the hormonal disorder, in which too much GH is secreted, thus initiates significance adenoma of pituitary gland, linked with severe insulin resistance and NIDDM Type-2 [93]. The higher levels of GH will trigger the extra production of insulin growth factor-1 (IGH-1), which exerts anabolic effects and subsequent propagation of bones, organs, cartilage, and tissues. The level of IGH-1 in cats determines the indication of acromegaly with definite insulin resistance that is why both $\mathrm{GH}$ and IGH-1 are considered for diagnosis [94,95]. The body demands of glucose are high due to hyperthyroidism, which explicates extra triiodothyronine $\left(\mathrm{T}_{3}\right)$ and thyroxine. Therefore, extra glucose is synthesized by natural process in the liver through lactic acid cycle and gluconeogenesis. Furthermore, this extra fatty acids and glycerol are also produced from lipolysis of adipose tissues in fasting time. The main resources of glycerol and amino acid are known to be lipolysis and proteolysis, respectively, based on the initiation of gluconeogenesis in certain conditions. Excessive anaerobic glycolysis and reduced insulin-stimulated glycogen create hyperthyroidism conditions. In result, the adipose tissues are reserved and hyperglycemia is maintained due to the anaerobic glycolysis of muscles, which produce lactate and convert to the glucose in liver [96].

Hormones and drugs which disturb insulin synthesis and activity play a crucial role in the induction 
of DM in animals. Hence, GF, thyroxine, glucagon, adrenaline, glucocorticoids, progestin, and artificial progesterone are mostly elaborated. Antagonist action is usually elicited on peripheral tissues, followed by collapse, damage to islets, and sustained hyperglycemia. Ultimately, if antagonism is no further organized in individuals, then animals will promote to IDDM condition. In general, necrosis is triggered by excessive adrenocorticism, whereas administration of dexamethasone and prednisolone represents antagonism in dogs, but these drugs hardly create hormonal abnormality in cats with simultaneous insulin resistance [97-99]. Structural and functional changes to epithelial tissues, especially in adrenal and pituitary glands, initiate hyperadrenocorticism in more than $50 \%$ of diagnosed cases affected by diabetes. Complete control of glucose in the blood (glycemia) was rarely established and diagnosed by typical signs.

Insulin antagonism linked with the high secretion of monoamines such as catecholamine in an animal with pheochromocytomas. Monoamines act as insulin inhibitors and produce a mild condition of intermediate glucose intolerance [100]. Diuretic drugs such as furosemide and hydrochlorothiazide induce glucose intolerance by the reduction of insulin-stimulated transport in adipose tissues and skeletal muscles [101].

\section{Herbal Therapies in the Treatment of Diabetes}

Herbal therapies in diabetes cover a wide range of studies and investigations. Mirhoseini et al. [102] published a paper, which introduced 27 medicinal plants used in animal models for the treatment of DM. Silymarin a well-known phytochemical (a standardized extract of the seeds of Silybum marianum) is believed to lessen inflammatory cytokines and oxidative stress biomarkers to prevent the IDDM type-1 in patients [103]. Herbal therapeutic agents such as Setarud (IMOD ${ }^{\mathrm{TM}}$ have the potential to reverse diabetes in streptozotocin-induced diabetic models [104]. Today, the utilization of herbal agents is passing a growing route in Asia, Europe, and North Africa as a tonic, anti-diabetic, anti-pyretic, and anti-allergic. Phlomis species such as Phlomis persica boiss or its extract significantly downregulate blood glucose level and are also effective against the complication that occurs due to the lipid peroxidation by antioxidant activity in streptozotocin-induced rats [105]. Similar investigation exhibited that Bixa orellana (annatto) extract decreased blood glucose levels in fasting normoglycaemic and streptozotocin-induced diabetic dogs by stimulating peripheral utilization of glucose [106]. The uses of conventional antidiabetic drugs along with herbal remedies have shown possible antihyperglycemic and therapeutic adjuncts of the oral route for controlling diabetes [107]. The therapies such as Setarud in combination with other polyphenols or flavonoids such as curcumin and quercetin have much stronger antioxidant effects in reversion of diabetes, yet preclinical and clinical trials should be elucidated for exact mechanism [108]. Besides herbal agents, other trace elements such as selenium act as antioxidants; however, patients with diabetes express an increased level of oxidative stress along with deficient selenium. Selenium exerts adverse effects on blood glucose hemostasis [109]. Bahadar et al. [110] reported that the massive exposure of arsenic and other environmental intoxication and pesticides play a significant role in the incidence of diabetes in humans as well as in animals, which is still unnoticed in non-social animals.

\section{Conclusion}

The spontaneous DM in small and wild animals comprises all types of diabetes defined in humans. In dogs, pregnancy, obesity, diestrus phase, and obstinate corpus luteum may generate diabetes. The appearance of DM in wild animals can be correlated with different stimuli such as confinement, food changes, low physical exercises, pancreatitis, and hormonal imbalance in the body. In cats, spontaneous NIDDM related to the islets of Langerhans amyloid disease is considered as the proper animal model but infrequently identified. Hormones, drugs, and pancreatic ketoacidosis collate to induce diabetes. To date, several herbal therapeutic agents with remedial potential are known to treat diabetes in humans and should be introduced in small and laboratory animals as well.

DM in animal models is not only a substantial area of research due to the various similarities with humans but also will play a key role in veterinary medicine and its progression. The investigation and the establishment of therapeutic protocols for diabetic animals comprise different issues. This should start with the recognition of etiological and risk factors in association with diabetes diagnosis of the DM initiators and suitable treatment protocols to terminate DM, in combination with other herbal therapies. This is noteworthy that human diagnosis, treatment, and classification protocol are not appropriate for animals, and the concurrent onset of DM in animals signifies the primary steps in creating unique and sufficient models for further studies.

\section{Authors' Contributions}

MA gave the idea, KN, and FM wrote the first draft of the manuscript. FK and FIH designed the figures. SM made the tables. Then, the whole manuscript critically revised by MA. All authors have read and approved the final version of the manuscript.

\section{Acknowledgments}

The authors declare that they did not have any funding source or grant to support this review.

\section{Competing Interests}

The authors declare that they have no competing interests. 


\section{References}

1. Catchpole, B., Adams, J.P., Holder, A.L., Short A.D., Ollier, W.E. and Kennedy, L.J. (2013) Genetics of canine diabetes mellitus: Are the diabetes susceptibility genes identified in humans involved in breed susceptibility to diabetes mellitus in dogs? Vet. J., 195: 139-147.

2. American Diabetes Association. (2014) Diagnosis and classification of diabetes mellitus. Diabetes Care, 37: S81-S90.

3. Robinson, W.F., Robinson, N.A. and Maxie, M.G. (2016) Jubb, Kennedy, and Palmar's Pathology of Domestic Animals. Elsevier, St. Louis, MO. p1-101.

4. Akash, M.S., Rehman, K. and Chen, S. (2013) An overview of valuable scientific models for diabetes mellitus. Curr. Diabetes Rev., 9: 286-93.

5. Ganguly, S. (2014) Canine diabetes mellitus: Diagnosis, adequate care and overall management practices involved. Int. J. Pharm. Life Sci., 5: 4022-4023.

6. Bolton, T.A., Cook, A., Steiner, J.M. and Fosgate, G.T. (2016) Pancreatic lipase immunoreactivity in serum of dogs with diabetic ketoacidosis. J. Vet. Intern. Med., 30: 958-963.

7. Fall, T., Hamlin, H.H., Hedhammar, A., Kämpe, O., and Egenvall, A. (2007) Diabetes mellitus in a population of 180,000 insured dogs: incidence, survival, and breed distribution. J. Vet. Intern. Med., 21: 1209.

8. Poppl, A.G., Mottin, T.S. and Gonzalez, F.H. (2013) Diabetes mellitus remission after resolution of inflammatory and progesterone-related conditions in bitches. Res. Vet. Sci., 94: 471-473.

9. Liao, S., Vickers, M.H., Stanley, J.L., Ponnampalam, A.P., Baker, P.N. and Perry, J.K. (2015) The placental variant of human growth hormone reduces maternal insulin sensitivity in a dose-dependent manner in C57BL/6J mice. Endocrinology, 157: 1175-1186.

10. Mattin, M.J., O’Neill, D.G., Church, D.B., McGreevy, P.D., Thomson, P.C. and Brodbelt, D.C. (2014) An epidemiological study of diabetes mellitus in dogs attending first opinion practice in the UK. Vet. Microbiol., 174: 349.

11. Davison, L. (2015) Diabetes mellitus and pancreatitis in dogs and cats-cause or effect? J. Small Anim. Pract., 56: 50-59.

12. Alvarez, M.S., Herrería-Bustillo, V., Utset, A.F. and Martínez, J. (2015) Juvenile diabetes mellitus and concurrent exocrine pancreatic insufficiency in a Labrador retriever: long-term management. J. Am. Anim. Hosp. Assoc., 51: 419-423.

13. O'Kell, A.L., Wasserfall, C., Catchpole, B., Davison, L.J., Hess, R.S., Kushner, J.A. and Atkinson, M.A. (2017) Comparative pathogenesis of autoimmune diabetes in humans, nod mice, and canines: Has a valuable animal model of Type 1 diabetes been overlooked? Diabetes, 66: 1443-1452.

14. Bellumori, T.P., Famula, T.R., Bannasch, D.L., Belanger, J.M. and Oberbauer, A.M. (2013) Prevalence of inherited disorders among mixed-breed and purebred dogs: 27, 254 cases (1995-2010). J. Am. Vet. Med. Assoc., 242: $1549-1555$.

15. Gilor, C., Niessen, S.J., Furrow, E. and Di Bartola, S.P. (2016) What's in a name? Classification of diabetes mellitus in veterinary medicine and why it matters. J. Vet. Intern. Med., 30: 927-940.

16. Ahlgren, K.M., Fall, T., Landegren, N., Grimelius, L., Von Euler, H., Sundberg, K., Lindblad-Toh, K., Lobell, A., Hedhammar, Å., Andersson, G. and Hansson-Hamlin, H. (2014) Lack of evidence for a role of islet autoimmunity in the aetiology of canine diabetes mellitus. PLoS One, 9(8): 105473.

17. Qadri, K., Ganguly, S., Praveen, P.K. and Wakchaure, R. (2015) Diabetes mellitus in dogs and its associated complications: A review. Int. J. Rec. Biotech., 3: 18-22.

18. Ciobotaru, E. (2013) Spontaneous diabetes mellitus in animals. In: Diabetes Mellitus-Insights and Perspectives.
InTech, Rijeka, Croatia.

19. Mao, J., Xia, Z., Chen, J. and Yu, J. (2013) Prevalence and risk factors for canine obesity surveyed in veterinary practices in Beijing, China. Prev. Vet. Med., 112: 438-42.

20. Adolphe, J.L., Silver, T.I., Childs, H., Drew, M.D. and Weber, L.P. (2014) Short-term obesity results in detrimental metabolic and cardiovascular changes that may not be reversed with weight loss in an obese dog model. $B r . J$. Nutr., 112: 647-656.

21. Broussard, J.L., Nelson, M.D., Kolka, C.M., Bediako, I.A., Paszkiewicz, R.L., Smith, L., Szczepaniak, E.W., Stefanovski, D., Szczepaniak, L.S. and Bergman, R.N. (2016) Rapid development of cardiac dysfunction in a canine model of insulin resistance and moderate obesity. Diabetologia., 59: 197-207.

22. Lai, M., Chandrasekera, P.C. and Barnard, N.D. (2014) You are what you eat, or are you? The challenges of translating high-fat-fed rodents to human obesity and diabetes. Nutr. Diabetes, 4: e135.

23. Jeong, E., Tan, R.M., Oh, H., Kim, K., Choi, Y., Kim, M.S., Kim, N. and Lee, K. (2016) Imaging diagnosis-endometrial mineralization in a dog. Vet. Radiol. Ultrasound., 57: 67-70.

24. Miceli, D.D., Pignataro, O.P. and Castillo, V.A. (2017) Concurrent hyperadrenocorticism and diabetes mellitus in dogs. Res. Vet. Sci., 115: 425-431.

25. Drynda, R., Peters, C.J., Jones, P.M., and Bowe, J.E. (2015) The role of non-placental signals in the adaptation of islets to pregnancy. Horm. Metab. Res., 47: 64-71.

26. Stanczyk, F.Z., and Bhavnani, B.R. (2014) Use of medroxyprogesterone acetate for hormone therapy in postmenopausal women: Is it safe? J. Steroid Biochem. Mol. Biol., 142: $30-38$.

27. Maqbool, F., Mostafalou, S., Bahadar, H. and Abdollahi, M. (2015) Review of endocrine disorders associated with environmental toxicants and possible involved mechanisms. Life Sci., 145: 265-273.

28. Hoenig, M. (2014) Comparative aspects of human, canine, and feline obesity and factors predicting progression to diabetes. Vet. Sci., 1(2): 121-135.

29. Scott-Moncrieff, J.C. (2010) Insulin resistance in cats. Vet. Clin. North Am. Small Anim. Pract., 40: 241-257.

30. Rand, J.S. (2013) Pathogenesis of feline diabetes. Vet. Clin. Small Anim. Pract., 43: 221-231.

31. Reusch, C.E. (2014) Feline diabetes mellitus. In: Feldman, E.C., Nelson, R.W., Reusch, C.E., ScottMoncrieff, J.C.R. and Behrend, E.N., editors. Canine and Feline Endocrinology. $4^{\text {th }}$ ed. Elsevier, St. Louis, MO. p258-314.

32. Will, S.E., Júnior, J.C., Alcântara, D., Fratini, P., Favaron, P.O., Miglino, M.A. and Neto, A.C. (2017) Stem cell therapy to restore pancreatic function in dogs and cats. Braz. J. Vet. Pathol., 5: 99-105.

33. Zini, E., Lunardi, F., Zanetti, R., Heller, R.S., Coppola, L.M., Ferro, S., Guscetti, F., Osto, M., Lutz, T.A., Reusch, C.E. and Cavicchioli, L. (2016) Endocrine pancreas in cats with diabetes mellitus. Vet Pathol., 53: 136-144.

34. Biden, T.J., Boslem, E., Chu, K.Y. and Sue, N. (2014) Lipotoxic endoplasmic reticulum stress, $\beta$ cell failure, and Type 2 diabetes mellitus. Trends Endocrinol. Metab., 25: 389-398.

35. Zheng, S., Zhou, H., Han, T., Li, Y., Zhang, Y., Liu, W. and $\mathrm{Hu}, \mathrm{Y}$. (2015) Clinical characteristics and beta cell function in Chinese patients with newly diagnosed Type 2 diabetes mellitus with different levels of serum triglyceride. $B M C$ Endocr. Disord., 15: 21.

36. Lewitt, M. S., Strage, E., and Church, D. (2016)An individual approach to feline diabetes care: A case report and literature review. Acta Vet. Scand., 58: 63.

37. O'neill, D.G., Gostelow, R., Orme, C., Church, D.B., Niessen, S.J., Verheyen, K. and Brodbelt, D.C. (2016) Epidemiology of diabetes mellitus among 193,435 cats 
attending primary-care veterinary practices in England. J. Vet. Intern. Med., 30: 964-972.

38. Nelson, R.W. and Reusch, C.E. (2014) Animal models of disease: Classification and etiology of diabetes in dogs and cats. J. Endocrinol., 222: 1-9.

39. Fortin, J.S. and Benoit-Biancamano, M.O. (2015) Wildlife sequences of islet amyloid polypeptide (IAPP) identify critical species variants for fibrillization. Amyloid, 22:194-202.

40. Varonin, J. (2016) Characterization of GFAP+ Islet Glial Cells. Doctoral Dissertation, University of California, San Francisco, CA.

41. Woldemeskel, M. (2012) A concise review of amyloidosis in animals. Vet. Med. Int., 2012: 1-11.

42. Bitan, G., Shanmugam, A., Lomakin, A., Schrader, T., Klarner, F.G., Talbiersky, P., Polkowska, J., Bastkowski, F., Sinha, S., and Frautschy, S. (2014) The Regents of the University of California, Assignee. Molecular Tweezers for the Treatment of Amyloid-Related Diseases. US Patent No. 8791092

43. Akter, R., Cao, P., Noor, H., Ridgway, Z., Tu, L.H., Wang, H., Wong, A.G., Zhang, X., Abedini, A., Schmidt, A.M. and Raleigh, D.P. (2016) Islet amyloid polypeptide: Structure, function, and pathophysiology. J. Diabetes Res., 2016: 1-18.

44. Henson, M.S., Hegstad-Davies, R.L., Wang, Q., Hardy, R.M., Armstrong, P.J., Jordan, K., Johnson, K.H., O'Brien, T.D. (2011) Evaluation of plasma islet amyloid polypeptide and serum glucose and insulin concentrations in nondiabetic cats classified by body condition score and in cats with naturally occurring diabetes mellitus. Am. J. Vet Res., 72: 1052-1058.

45. O'Brien, T., Butler, P., Westermark, P. and Johnson, K. (1993) Islet amyloid polypeptide: A review of its biology and potential roles in the pathogenesis of diabetes mellitus. Vet. Pathol., 30: 317-332.

46. Li, L.O., Klett, E.L. and Coleman, R.A. (2010) Acyl-CoA synthesis, lipid metabolism and lipotoxicity. Biochim. Biophys. Acta. Mol. Cell Biol. Lipids, 1801: 246-251.

47. Feldhahn, J., Rand, J. and Martin, G. (1999) Insulin sensitivity in normal and diabetic cats. J. Feline Med. Surg, 1: 107-115.

48. Mori, A., Lee, P., Takemitsu, H., Iwasaki, E., Kimura, N., Yagishita, M., Hayasaka, M., Arai, T. (2009) Decreased gene expression of insulin signaling genes in insulin-sensitive tissues of obese cats. Vet. Res. Commun., 33: 315-329.

49. Laflamme, D. (2012) Companion animals symposium: Obesity in dogs and cats: What is wrong with being fat? $J$. Anim. Sci., 90: 1653-1662.

50. Rand, J.S., Fleeman, L.M., Farrow, H.A., Appleton, D.J. and Lederer, R. (2004) Canine and feline diabetes mellitus: Nature or nurture? J. Nutr., 134: 2072S-2080S.

51. Zoran, D.L. (2010) Obesity in dogs and cats: A metabolic and endocrine disorder. Vet. Clin. North Am. Small Anim. Pract., 40: 221-239.

52. Rosenblum, I., Barbolt, T. and Howard, C. Jr. (1980) Diabetes mellitus in the chimpanzee (Pan troglodytes). $J$. Med. Primatol., 10: 93-101.

53. Davis, K., Bell, R., Wilhelmsen, C., Langford, M.J., Montali, R.J. (1994) Immunohistochemical analysis of spontaneous pancreatic islet amyloid deposits in nonhuman primates. Vet. Pathol., 31: 479-479.

54. De Koning, E., Bodkin, N., Hansen, B. and Clark, A. (1993) Diabetes mellitus in Macaca mulatta monkeys is characterised by islet amyloidosis and reduction in beta-cell population. Diabetologia, 36: 378-384.

55. Howard, C. Jr., and Palotay, J. (1975) Spontaneous diabetes mellitus in Macaca cyclopis and Mandrillus leucophaeus: Case reports. Lab. Anim. Sci., 25: 191-196.

56. O’Brien, T., Wagner, J., Litwak, K., Carlson, C.S., Cefalu, W.T., Jordan, K., Johnson, K.H. and Butler, P.C. (1996) Islet amyloid and islet amyloid polypeptide in cynomolgus macaques (Macaca fascicularis): An animal model of human non-insulin-dependent diabetes mellitus. Vet.
Pathol., 33: 479-485.

57. Hubbard, G., Steele, K., Davis, K. and Leland, M. (2002) Spontaneous pancreatic islet amyloidosis in 40 baboons. J. Med. Primatol., 31: 84-90.

58. Hubbard, G.B., Lee, D.R., and Steele, K.E., Lee, S., Binhazim, A.A. and Brasky, K.M. (2001) Spontaneous amyloidosis in twelve chimpanzees, Pan troglodytes. J. Med. Primatol., 30: 260-267.

59. Wagner, J.D., Carlson, C.S., O'Brien, T.D., Anthony, M.S., Bullock, B.C. and Cefalu, W.T. (1996) Diabetes mellitus and islet amyloidosis in cynomolgus monkeys. Lab. Anim. Sci., 46: 36-41.

60. Gamble, K.C., Garner, M.M., Krause, L. and Alvarado, T.P. (2004) Pancreatic islet fibrosis in rock hyraxes (Procavia capensis), Part 1: Case histories, clinical pathology, and epizootiology. J. Zoo Wildlife Med., 35: 361-369.

61. Meegan, J.M., Sidor, I.F., Steiner, J.M., Sarran, D. and Dunn, J.L. (2008) Chronic pancreatitis with secondary diabetes mellitus treated by use of insulin in an adult California sea lion. J. Am. Vet. Med. Assoc., 232: 1707-1712.

62. Kollias, G. Jr. Calderwood-Mays, M. and Short, B. (1984) Diabetes mellitus and abdominal adenocarcinoma in a Jaguar receiving megestrol acetate. J. Am. Vet. Med. Assoc., 185: 1383-1386.

63. Prowten, A.W. (1975) Case report: Diabetes mellitus in an African spotted leopard. Am. Assoc. Zoo Vet., : 215-217.

64. Pirarat, N., Kesdangsakolwut, S., Chotiapisitkul, S. and Assarasakorn, S. (2008) Spontaneous diabetes mellitus in captive Mandrillus sphinx monkeys: A case report. J. Med. Primatol., 37: 162-165.

65. Remick, A., Wood, C., Cann, J., Gee, M.K., Feiste, E.A., Kock, N.D. and Cline JM. (2006) Histologic and immunohistochemical characterization of spontaneous pituitary adenomas in fourteen cynomolgus macaques (Macaca fascicularis). Vet. Pathol. Online, 43: 484-493.

66. Heidt, G., Conaway, H., Frith, C. and Farris, H. Jr. (1984) Spontaneous diabetes mellitus in a captive golden-mantled ground squirrel, Spermophilus lateralis (Say). J. Wildlife Dis., 20: 253-255.

67. Gull, J., Steinmetz, H., Clauss, M., Dorothea, B., Pete, O., Christian, J.W. and Jean-Michel, H. (2009) Occurrence of cataract and fatty liver in captive plains viscachas (Lagostomus maximus) in relation to diet. J. Zoo Wildlife Med., 40: 652-658.

68. Weir, B.J. (1974) The development of diabetes in the tucotuco (Ctenomys talarum). Proc. R. Soc. Med., 67: 843.

69. Niklasson, B., Heller, K.E., Schønecker, B., Bildsoe, M., Daniels, T., Hampe, C.S., Widlund, P., Simonson, W.T., Schaefer, J.B., Rutledge, E., Bekris, L., Lindberg, A.M., Johansson, S., Ortqvist, E., Persson, B. and Lernmark, A. (2003) Development of Type 1 diabetes in wild bank voles associated with islet autoantibodies and the novel ljungan virus. J. Diabetes Res., 4: 35-44.

70. Niklasson, B., Hörnfeldt, B., Nyholm, E., Niedrig, M., Donoso-Mantke, O., Gelderblom, H.R. and Lernmark, A. (2003) Type 1 diabetes in Swedish bank voles (Clethrionomys glareolus): Signs of disease in both colonized and wild cyclic populations at peak density. Ann. N. Y. Acad. Sci., 1005: 170-175.

71. Sitbon, G. and Mialhe, P. (1979) The endocrine pancreas of birds. J. Physiol., 76: 5-24.

72. Braun, E.J. and Sweazea, K.L. (2008) Glucose regulation in birds. Comp. Biochem. Physiol. Biochem. Mol. Biol., 151: 1-9.

73. Pollock, C. (2002) Carbohydrate regulation in avian species. In: Seminars in Avian and Exotic Pet Medicine. Elsevier, New York. p57-64.

74. Van Der Kolk, J.H., Hoyer, M.J., Verstappen, F.A., Wolters, M.S., Treskes, M., Grinwis, G.C. and Kik, M.J. (2011) Diabetes mellitus in a 50-year-old captive Asian elephant (Elaphas maximus) bull. Vet. Quart., 31: 99-101.

75. Gancz, A.Y., Wellehan, J.F., Boutette, J., Malka, S., 
Lee, S.E., Smith, D.A. and Taylor, M. (2007) Diabetes mellitus concurrent with hepatic haemosiderosis in two macaws (Ara severa, Ara militaris). Avian Pathol., 36: 331-336.

76. Iancu, T.C., Ward, R.J. and Peters, T.J. (1990) Ultrastructural changes in the pancreas of carbonyl iron-fed rats. J. Ped. Gastroenterol. Nutr., 10: 95-101.

77. Wallner-Pendleton, E.A., Rogers, D., and Epple, A. (1993) Diabetes mellitus in a red-tailed hawk (Buteo jamaicensis). Avian Pathol., 22: 631-635.

78. Desmarchelier, M. and Langlois, I. (2008) Diabetes mellitus in a Nanday conure (Nandayus nenday). J. Avian Med. Surg., 22: 246-254.

79. Pilny, A.A. and Luong, R. (2005) Diabetes mellitus in a chestnut-fronted macaw (Ara severa). J. Avian Med. Surg., 19: 297-302.

80. Candeletta, S.C., Homer, B.L., Garner, M.M. and Isaza, R. (1993) Diabetes mellitus associated with chronic lymphocytic pancreatitis in an African grey parrot (Psittacus erithacus erithacus). J. Assoc. Avian Vet., 7: 39-43.

81. Phalen, D.N., Falcon, M. and Tomaszewski, E.K. (2007) Endocrine pancreatic insufficiency secondary to chronic herpesvirus pancreatitis in a cockatiel (Nymphicus hollandicus). J Avian Med. Surg, 21: 140-145.

82. Tsai, S., Park, J., Hirai, K. and Itakura, C. (1993) Herpesvirus infections in psittacine birds in Japan. Avian Pathol., 22: 141-156.

83. Gravendyck, M., Balks, E., Schröder-Gravendyck, A.S., Eskens, U., Frank, H., Marchang, R.E. and Kaleta, E.F. (1998) Quantification of the herpesvirus content in various tissues and organs, and associated post mortem lesions of psittacine birds which died during an epornithic of Pacheco's parrot disease (PPD). Avian Pathol., 27: 478-489.

84. Watson, P., Roulois, A., Scase, T., Holloway, A. and Herrtage, M.E. (2011) Characterization of chronic pancreatitis in English Cocker Spaniels. J. Vet. Intern. Med., 25: 797-804.

85. Watson, P.J. and Herrtage, M.E. (2004) Use of glucagon stimulation tests to assess $\beta$-cell function in dogs with chronic pancreatitis. J. Nutr., 134: 2081S-2083S.

86. Watson, P., Archer, J., Roulois, A., Scase, T. and Herrtage, M.E. (2013) Observational study of 14 cases of chronic pancreatitis in dogs. Vet. Rec. Case Rep., 1: ec4912.

87. Hess, R.S., Kass, P.H., Shofer, F.S., Van Winkle, T.J., Washabau, R.J. (1999) Evaluation of risk factors for fatal acute pancreatitis in dogs. J. Am. Vet. Med. Assoc. (USA), 214: 46-51.

88. Holliman, J.H. (1992) Hepatobiliary system and exocrine pancreas. In: Pathology. Springer, Berlin. p147-162.

89. Mizuno, T., Hiraoka, H., Yoshioka, C., Takeda, Y., Matsukane, Y., Shimoyama, N., Morimoto, M., Hayashi, T. and Okuda, M. (2009) Superficial necrolytic dermatitis associated with extrapancreatic glucagonoma in a dog. Vet. Dermatol., 20: 72-79.

90. Umpierrez, G.E., Murphy, M.B., and Kitabchi, A.E. (2002) Diabetic ketoacidosis and hyperglycemic hyperosmolar syndrome. Diabetes Spectr., 15: 28-36.

91. Kerl, M.E. (2001) Diabetic ketoacidosis: Pathophysiology and clinical and laboratory presentation. Compendium, 23: $220-228$.

92. De Causmaecker, V., Daminet, S. and Paepe, D. (2009) Diabetes ketoacidosis and diabetes ketosis in 54 dogs: A retrospective study. Vlaams Diergeneeskundig Tijdschrift, 78: 327-337.

93. Niessen, S., Petrie, G., Gaudiano, F., Khalid, M., Smyth, J.B., Mahoney, P. and Church, D.B. (2007) Feline acromegaly: An underdiagnosed endocrinopathy? J. Vet. Intern. Med., 21: 899.

94. Fracassi, F., Gandini, G., Diana, A., Preziosi, R., Ingh, T.S., Famigli-Bergamini, P. and Kooistra, H.S. (2007) Acromegaly due to a somatroph adenoma in a dog. Domestic Anim. Endocrinol., 32: 43-54.

95. Niessen, S.J., Church, D.B. and Forcada, Y. (2013) Hypersomatotropism, acromegaly, and hyperadrenocorticism and feline diabetes mellitus. Vet. Clin. Small Anim. Pract., 43: 319-350.

96. Gierach, M., Gierach, J., and Junik, R. (2014) Insulin resistance and thyroid disorders. Endokrynol. Polska., 65: 70-76.

97. Hibbert, A. (2016) When can the Dermatologist cause Problems for the Internist? Insponsors $8^{\text {th }}$ World Congress Veterinary Dermatology. p308.

98. Valentin, S.Y., Cortright, C.C., Nelson, R.W., Pressler, B.M., Rosenberg, D., Moore, G.E. and Scott-Moncrieff, J.C. (2014) Clinical findings, diagnostic test results, and treatment outcome in cats with spontaneous hyperadrenocorticism: 30 cases. J. Vet. Intern. Med., 28: 481-487.

99. Kimitsuki, K., Boonsriroj, H., Kojima, D., and Park, C.H. (2014) A case report of feline pituitary carcinoma with hypercortisolism. J. Vet. Med. Sci., 76: 133-138.

100. Charmandari, E., Nicolaides, N.C. and Chrousos, G.P. (2014) Adrenal insufficiency. Lancet, 383: 2152-2167.

101. Fathallah, N., Slim, R., Larif, S., Hmouda, H. and Salem, C.B. (2015) Drug-induced hyperglycaemia and diabetes. Drug Safety, 38: 1153-1168.

102. Mirhoseini, M., Baradaran, A. and Rafieian-Kopaei, M. (2013) Medicinal plants, diabetes mellitus and urgent needs. J. Herb. Med. Pharmacol., 2: 53-54.

103. Gargari, B.P., Mobasseri, M., Valizadeh, H. and AsghariJafarabadi, M. (2015) Effects of Silybum marianum (L.) Gaertn. (silymarin) Extract supplementation on antioxidant status and hs-CRP in patients with Type 2 diabetes mellitus: A randomized, triple-blind, placebo-controlled clinical trial. Phytomedicine, 22: 290-296.

104. Sadeghi, H., Monfared, S.S.M.S., Habibollahzadeh, E., Sadeghi, H., and Baeeri, M. (2009) Effect of setarud $\left(\mathrm{IMOD}^{\mathrm{TM}}\right)$ as a new herbal drug on streptozotocin-induced diabetes. Toxicol. Lett., 189: S128.

105. Sarkhail, P., Fadyevatan, S. and Abdollahi, M. (2008) Antioxidant effect of Phlomis persica Boiss. in rats with streptozotocin-induced diabetes. Planta Med., 74: PA165.

106. Russell, K., Omoruyi, F., Pascoe, K. and Morrison, E.S.A. (2008) Hypoglycaemic activity of Bixa orellana extract in the dog. Methods Find. Exp. Clin. Pharmacol., 30: 301.

107. Farzaei, M.H., Rahimi, R., Farzaei, F. and Abdollahi, M. (2015) Traditional medicinal herbs for the management of diabetes and its complications: An evidence-based review. Int. J. Pharmacol., 11: 874-887.

108. Tabatabaei-Malazy, O., Larijani, B. and Abdollahi, M. (2013) A novel management of diabetes by means of strong antioxidants' combination. J. Med. Hypotheses Ideas, 7: 25-30.

109. Faghihi, T., Radfar, M., Barmal, M., Amini, P., Qorbani, M., Abdollahi, M. and Larijani, B. (2014) A randomized, placebo-controlled trial of selenium supplementation in patients with Type 2 diabetes: Effects on glucose homeostasis, oxidative stress, and lipid profile. Am. J. Ther., 21: 491-495.

110. Bahadar, H., Mostafalou, S. and Abdollahi, M. (2014) Growing burden of diabetes in Pakistan and the possible role of arsenic and pesticides. J. Diabetes Metab. Disord., 13: 1 .

\section{$* * * * * * * *$}

